\title{
Rhizosphere microbiota interfers with plant-plant interactions
}

\author{
A. Sanon • Z. N. Andrianjaka • Y. Prin • R. Bally • \\ J. Thioulouse $\cdot$ G. Comte $\cdot$ R. Duponnois
}

Published online: 8 August 2009

(C) Springer Science + Business Media B.V. 2009

\section{Erratum to: Plant Soil 321:259-278 DOI 10.1007/s11104-009-0010-5}

The original article was inadvertently published with incorrect affiliation of the authors Z.N. Adrianjaka, R. Bally and G. Comte and with an incorrect version of Fig. 3. The correct affiliation, image and caption is shown here:

Responsible Editor: Philippe Lemanceau.

The online version of the original article can be found at http:// dx.doi.org/10.1007/s11104-009-0010-5.
Y. Prin

CIRAD, UMR 113 CIRAD/INRA/IRD/SUP-AGRO/UM2, Laboratoire des Symbioses Tropicales et Méditerranéennes (LSTM),

TA10/J, Campus International de Baillarguet, Montpellier, France

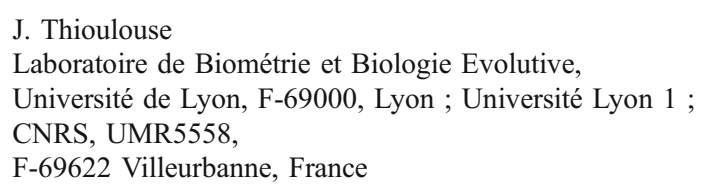



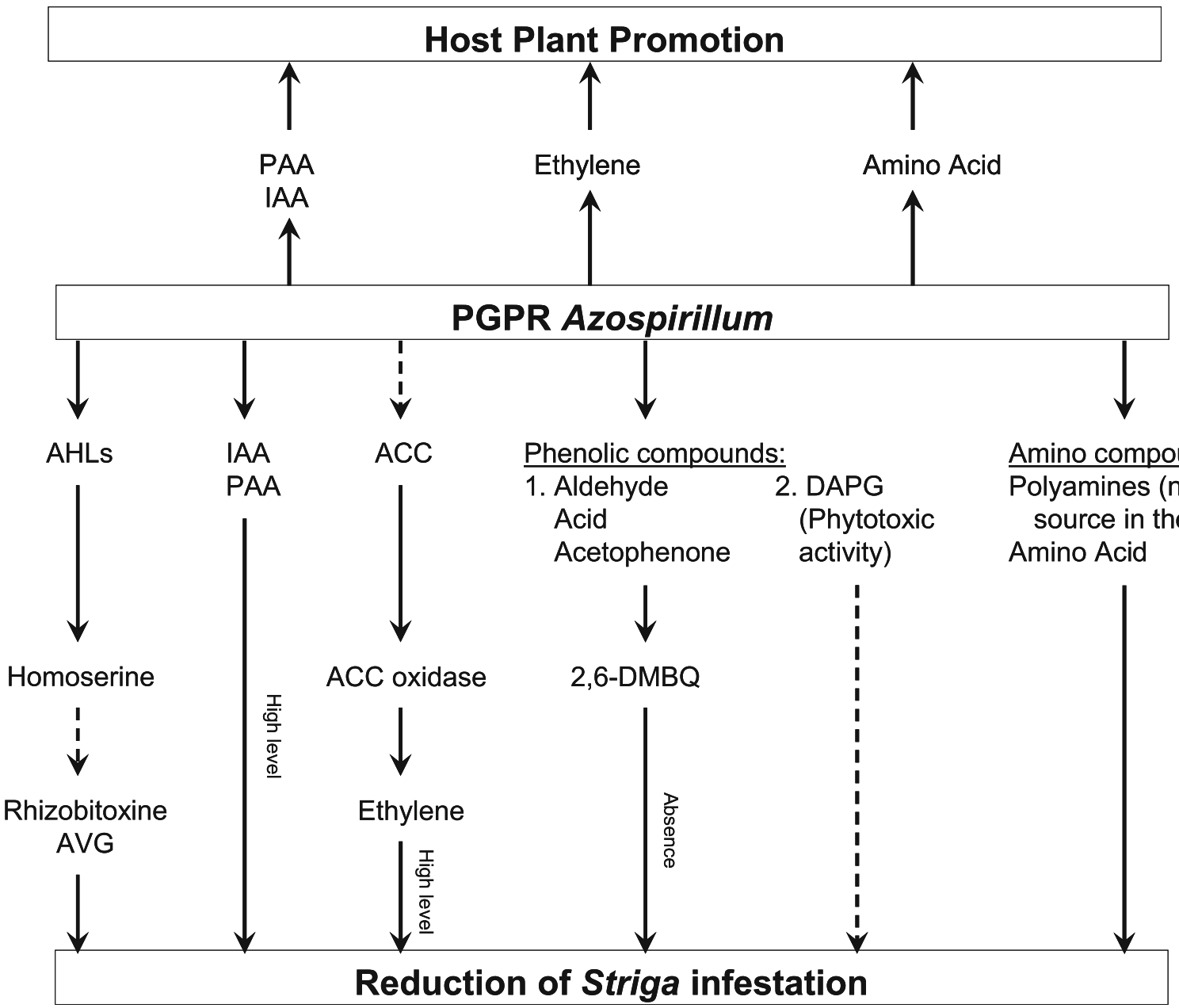

Fig. 3 Hypothetic molecular impact of PGPR Azospirillum in the tripartite interaction Azospirillum/Host plant/Striga spp. 1-aminocyclopropane-1-carboxylate (ACC), Acyl-homoserine lactone (AHLs), Aminoethoxyvinyl Glycine (AVG), Diacetylphlorogluci- nol (DAPG), 2,6-dimethyl-p-benzoquinone (2,6-DMBQ), Indole acetic acid (IAA), Phenylacetic acid (PAA); - - - - unprouved, prouved 